\title{
Retraduir Sòfocles*
}

\author{
Joan Casas \\ Escriptor i traductor \\ casasfuster@gmail.com
}

\section{Resum}

En Feliu Formosa i jo som els autors d'un volum de versions en vers de Sòfocles. En el cas dels textos teatrals clàssics, la retraducció és, tot sovint, el primer cas amb vista a una nova posada en escena, i el treball, en aquest cas, es fa en unes condicions molt particulars. Potser el problema de les retraduccions que vam fer en Feliu Formosa i jo va ser que no tenien aquesta destinació, sinó només la de ser el fonament d'un possible treball pedagògic. Tot i que generalment la recepció crítica de les traduccions és escassa, aquestes van ser objecte d'un sòlid article que no les tractava amb gaires miraments. Sense discutir les raons del crític, apuntarem, tanmateix, algunes precisions.

Paraules clau: retraduir; teatre clàssic; traduir el vers; traduir per a l'escena; traducció i crítica; Sòfocles

\section{Abstract. Retranslating Sophocles}

Feliu Formosa and me are the authors of a volume of verse versions of Sophocles. In the case of classical theatrical texts, retranslation is often the first step in the way of a new staging, and the work, in this case, is done under very particular conditions. Perhaps the problem with the retranslations that Feliu Formosa and me have done is the fact that they did not have this destination, but only that of being the starting point for a possible pedagogical work. Although the critical reception of translations is generally very poor, in that case they were the subject of a solid article that did not treat them with much consideration. Without discussing the critic's reasons, however, some details are pointed out.

Keywords: retranslation; classical theater; translation of verse; translation for the stage; translation and criticism; Sophocles

\section{Sumari}

\section{La retraducció de textos 3. Conclusió teatrals clàssics}

2. Traductors i crítics

* Tragèdies. Trad. de Joan Casas i Feliu Formosa. Barcelona: Comanegra-Institut del Teatre, 2019. 


\section{La retraducció de textos teatrals clàssics}

Establim una qüestió de principi. La millor forma d'interrogar culturalment un text teatral, de qualsevol època, és posar-lo en escena.

En el cas dels textos teatrals clàssics, la retraducció és, tot sovint, el primer treball que es fa sobre el text amb vista a un projecte d'escenificació. En aquest cas, el traductor treballa en sintonia amb un director que busca en el text, en general, un determinat efecte de versemblança, o un cert joc de proximitat o de distància. El director pot voler un text en vers o, contràriament, un text en prosa. El director pot voler un text molt proper, molt «actualitzat», o, en sentit contrari, un text que a través de la distància aconsegueixi uns determinats efectes d'estranyament o de hieratisme. El director pot voler un determinat ritme, una determinada prosòdia, i condicionar d'aquesta manera la retòrica i la sintaxi de la traducció.

Quan un traductor treballa amb un director d'escena, és possible que entre tots dos sotmetin el text a un treball d'interpretació, d'hermenèutica, molt aprofundit, imprescindible per comprendre i per transmetre allò que té lloc a l'escenari. La posada en escena s'interroga a més sobre la relació de la paraula amb l'acció física, i sobre l'efectivitat de totes dues coses, i pot preferir determinades solucions en funció d'aquests criteris. I encara pot ser que el text, en les lectures inicials dels actors, es modifiqui en funció de l'eficàcia oral o de l'adequació amb els hàbits lingüístics de l'actor.

L'operació de preparar per a l'escenari un vell text teatral pot ser una traducció o una versió. Val a dir que la diferència entre traduccions i versions pot tenir una substanciosa dimensió econòmica, una dimensió de vegades fraudulenta, perquè quan es tracta de clàssics amb drets d'autor lliures, massa vegades passa que textos que es declaren com a «versions» s'han treballat en realitat a partir de traduccions els autors de les quals no han cobrat ni un ral dels seus drets de representació. De totes maneres, la frontera entre les traduccions i les versions és tot sovint difícil d'establir.

Quina era la raó de ser del volum de tragèdies de Sòfocles que vam fer en Feliu Formosa i jo mateix? No era una demanda que ens haguessin fet, com hauria estat el cas d'un projecte de posada en escena, sinó que partia de la constatació nostra d'una mancança i era alhora una aposta que fèiem: una aposta per ajudar a rellançar el vers i els clàssics grecs en l'ensenyament de la pràctica teatral. Una aposta que, d'altra banda, no és gens segur que hagi tingut una gran eficàcia. Almenys fins ara. ${ }^{1}$

Segurament si haguessin estat textos per a l'escenificació, haurien tingut una altra dimensió, una altra densitat, perquè haurien estat treballats pel diàleg amb la posada en escena, que enriqueix, concreta, precisa les decisions, o bé, de vegades, les contradiu, les fa impossibles.

Però en aquest cas no vam traduir per a cap projecte de posada en escena, ni tan sols per a aquesta mena de posada en escena modesta, domèstica i pedagògica

1. Sobre la raó de ser de les nostres versions de Sòfocles es pot llegir el text que vam redactar per a la revista Visat: $<$ http://www.visat.cat/newsletter/article_2016.php?id=27\&idArt=98>. 
que és un taller d'escola, amb l'única excepció de la versió d'Electra que va fer el Feliu i que també està inclosa al volum.

\section{Traductors i crítics}

L'aportació de la crítica a la traducció es limita a ser, en general, un adjectiu pelat: ajustada, magnífica, correcta, brillant, encertada... Fins i tot delicada. Ja és més infrequient el cas que algú gosi dir que una traducció és pesada, errada, enfarfegosa o que és un mer disbarat.

Però aquesta vegada les nostres traduccions van passar per l'adreçador de la crítica raonada en la forma dels dos articles (de fet un article extens partit per exigències editorials) que hi va dedicar l'Eloi Creus a la magnífica publicació digital La Lectora. ${ }^{2}$

Si l'objectiu era l'ensenyament del vers, diu el jove crític, ens hi vam ben lluir. I assenyala errades mètriques, de mesura i d'accentuació, hiats forçats que volien convertir octosílllabs passadors en decasílllabs impossibles, etcètera. ${ }^{3}$ Aquesta mena d'errades afectarien sobretot les meves traduccions, no tant les del Feliu. Discuteix també la coherència de la prosòdia que el text proposa («maledicció» en cinc sílllabes o «desgràcies» en quatre, al costat de formes molt més populars com «pro» o «per'xò»). El crític diu que hauria estat més comprensible que persones amb obra pròpia, com en Feliu o jo, haguéssim optat per allò que ell anomena «versions de poeta», i esmenta, a tall d'exemple, «Les troianes» de Sartre, «L'Orestea» de Pasolini o l' «Antígona» de Raboni. I suggereix que deixem les traduccions pròpiament dites en mans dels que poden traduir perquè saben grec (i cita en aquest sentit una frase del malaguanyat Carles Miralles). El nostre treball no hauria hagut de sortir de l'àmbit escolar, segons el crític.

No és aquest el lloc per discutir la crítica de l'Eloi Creus, però sí per reprendre alguns dels seus arguments. El primer és aquest especiós concepte de si es pot traduir «sense saber grec».

La primera resposta és immediata per òbvia: no, però sí. Hi ha les traduccions indirectes. Però les nostres tampoc eren ben bé traduccions indirectes, és a dir, fetes a través d'una llengua intermediària. Seria reduccionista i fals dir que vam establir els nostres textos a partir de la traducció francesa de Jean Grosjean. Vam tenir presents, i vam usar, un ventall de traduccions en més d'una llengua, entre les quals les traduccions en prosa de Carles Riba a la «Bernat Metge» hi van jugar un paper no pas menor.

Però també és veritat que jo vaig dubtar molt d'anomenar versions allò que havíem fet. El concepte de versió em semblava que incloïa una intervenció del versionador sobre el sentit o sobre la forma que anava més enllà d'allò que fa el traductor. I jo crec que, llevat de la decisió de versificar en decasílllabs les parts

2. Vegeu <https://lalectora.cat/2020/03/24/la-tragedia-del-decasillab-sobre-el-sofocles-de-joancasas-i-feliu-formosa-i/>.

3. Vegeu <https://lalectora.cat/2020/03/31/la-tragedia-del-decasillab-sobre-el-sofocles-de-joancasas-i-feliu-formosa-ii/>. 
dialogades, la nostra intenció era la de fer amb el text original allò mateix que fa un traductor.

Allò que l'Eloi Creus anomena «versions de poeta», si més no en el cas dels exemples que proposa, trobo jo que tenen més a veure amb les traduccions o versions per a la posada en escena de què parlava més amunt.

«Les troianes» de Jean-Paul Sartre va ser un encàrrec del Théâtre National Populaire, que aleshores, l'any 1965, dirigia George Wilson, per bé que la posada en escena la va signar Michael Cacoyannis; «L'Orestea» de Pasolini va ser un encàrrec de Vittorio Gassmann per al seu Teatro Popolare Itinerante, un envelat de circ que girava per Itàlia presentant grans clàssics, cinc anys anterior a l'encàrrec sartrià; l' "Antígona» de Raboni va ser també un encàrrec de la temporada 2000 de 1'Istituto Nazionale del Dramma Antico per ser representat al Teatre Grec de Siracusa, a Sicília, sota la direcció de Patrice Kerbrat. El grau de «llibertat poètica» de cadascun d'aquests encàrrecs va ser variable.

Sartre ja havia experimentat allò que podríem qualificar d'adaptació lliure amb «Les mosques», i quan va rebre l'encàrrec de «Les troianes» va mirar de cenyir-se molt més al text antic, que ell podia llegir perfectament per la seva formació acadèmica. Quan el text es va editar es va subtitular com una «adaptació del grec antic». I, de fet, a casa nostra, almenys fins ara, quan s'han representat Les troianes, han estat sempre les de Sartre, retraduïdes al català per Manuel de Pedrolo.

Pasolini va tenir només tres mesos per servir a Vittorio Gassmann el text que li havia demanat. Va haver d'anar de pressa. Va tenir presents, segons ell mateix, traduccions filològiques en diverses llengües, però es va refiar molt més d'allò que anomenava el seu «instint» i de l'eina lingüística i poètica que havia anat elaborant amb el gran recull «Les cendres de Gramsci», que havia estat publicat l'any 1957.

Allò que va fer Giovanni Raboni amb la seva «Antígona», finalment, s'assembla molt més a allò que vam provar de fer nosaltres mateixos si deixem de banda la qüestió de l'encàrrec, que en el nostre cas era només proposta i aposta. Tot i que el poeta italià tampoc no és hel-lenista, amb la crossa intermediària de les traduccions que coneix fa un intent de cenyir-se al text original de molt a la vora, fins a l'extrem que la majoria del text de les parts dialogades és una traducció vers a vers que transforma els trímetres iàmbics en hendecasílllabs italians. I quant a la matèria mètrica dels versos, es dona moltes llibertats en l'accentuació (diu que ha fet servir un hendecasílllab «sovint volgudament degradat i "insonoritzat" per una extrema varietat d'accents no canònics»). ${ }^{4} \mathrm{Fa}$ uns versos, doncs, que considera prosòdicament i dramàticament plausibles i eficaços, però la irregularitat dels quals l'hauria pogut assenyalar un crític.

4. Vegeu Raboni, Giovanni. L'opera poètica. Milà: Mondadori, 2006, p. 1743. 


\section{Conclusió}

La retraducció dels textos clàssics té una rellevància especial en el cas del teatre, perquè s'articula amb les idees vigents en cada moment i pròpies de cada artista, de veritat i de versemblança escènica. La nostra proposta de retraducció de Sòfocles, més modestament, es va fer amb una vocació pedagògica, i segurament té com una de les limitacions el fet de no ser filla de cap projecte concret d'escenificació, de vinculació amb un públic. 
